\title{
MOLECULAR AND BIOLOGICAL IDENTIFICATION OF METARHIZIUM ANISOPLIAE EG016 AS POTENTIAL BIOCONTROL AGENT INFECTED SPODOPTERA EXIGUA AGAINST SPODOPTERA LITTORALIS (LEPIDOPTERA: NOCTUIDAE)
}

\author{
LOTFY, DALIA E. ${ }^{1}$; A. G. ABDELHAMID²; \\ KH. A. EL-DOUGDOUG ${ }^{3}$
}

1. Plant Protection Research Institute, ARC, Giza, Egypt

2. Botany Department, Faculty of Science, Benha University, Egypt

3. Agricultural Microbiology Department, Faculty of Agriculture, Ain-Shams University, Egypt

(Manuscript received 31 July 2016 )

\begin{abstract}
$\mathrm{E}$ ntomopathogenic Merarhizium fungus infects and kills insect pests in the green house and is used as agent in biological control. In this study, it was isolated from naturally infected pupae of Spodoptera exiguae which known to infest cabbage plants. The infection resulted in color change, malformation, cell death as well as fungal mycelium growth. Metarhizium sp. was isolated from infected pupae on SDYA Sabouraud dextrose yeast extract agar specific medium and showed fully colonies with round shape on medium. The fungus was isolated from pure single colony on SYDA medium by hyphal tip method. The purified isolate was identified based on morphological characteristics including hyaline and branched conidiophore,formation of a sporulating layer,single phialides or in pairs, conidia produced in chains, compacted into columns and long-ovoid to cylindrical shape was observed. Pathogenicity potential was $66.8 \%$ after 12 days of treatment. The molecular identification was conducted via 18srDNA gene amplification (335 bp PCR product resulted) and sequencing recorded in gene bank M. anisopliae EG016 (KU965593) isolate.
\end{abstract}

Key words: Entomopathogenic fungi, Spodoptera exigua, Isolation, Identification, DNA, PCR, Nucelotide Sequences.

\section{INTRODUCTION}

Entomopathogenic fungi represent effective and promising biotic components in the natural regulation of arthropods (Meyling and Eilenberg, 2007). There are more than 750 entomopathogenic fungal species identified worldwide. The genus Metarhizium (Ascomycetes) includes multiple species such as $M$. anisopliae, $M$. flavoviride and $M$. acridum and considered as the best characterized entomopathogens (Meyling and Eilenberg, 2007). They have the potential to infect a wide range of insects compromising agronomically important pests such as locusts. Termites, beetle larvae and spittlebugs. The taxonomy of Metarhizium, particularly $M$. 
anisopliae mophospecies has been performed through applying morphological, biochemical and molecular based characteristics (Pantou et al., 2003).

Numerous biological control agents were developed using Metarhizium species. The Deuteromycete fungus Metarhizium anisopliae infects insect pests of commercial importance and has been studied extensively as a possible biological control agent as potential commercial product (Barra et al., 2013). The maximum germination temperature of many isolates of $M$. anisopliae is about $37^{\circ} \mathrm{C}$. It is widely dispersed in nature and commonly isolated from infected insect or soil (Razinger et al., 2014).

In addition, Entomopathogenic fungi for instance M. anisopliae, B. bassiana and Bacillus thuringiensis were tested against the insect pests (the diamondback moth, the cabbage worm and beet armyworm) in the green house and in the field (Sabbour and Sahab, 2005).

The present work aims to isolation, of a Metarhizium fungus that could be a promising biological control agent from Spodoptera exigua and further identification using Biological and Pathogenicity characteristics as well as 18srDNA gene amplification and sequencing.

\section{MATERIALS AND METHODS}

Isolation of Metarhizium sp.: The naturally infected pupae of Spodoptera exigua showing fungal symptoms were collected from fields in which cabbage (Brassica oleracea) was infested in Sharkiya governorates. Pupae were surface sterilized using sodium hypochlorite $(1 \%)$ for 30 second, then washed several times by sterilized distilled water and dried carefully using sterilized filter paper. Sterilized insect surface was transferred onto Sabouraud dextrose yeast extract agar (SDYA) medium; containing $1 \%$ peptone, $0.2 \%$ yeast extract, $4 \%$ dextrose and $1.5 \%$ agar in distilled water and incubated at $25^{\circ} \mathrm{C}$ for 14 days. The fungal growth was investigated daily to detect any growth of fungal colonies. All fungal colonies were reinoculated on SDYA medium for maintenance and purification (Hashim et al., 2002).

\section{Purification of the isolated fungus.}

The fungal isolate was purified using hyphal tips from the external growth by taking aloopful, followed by inoculation on appropriate SYDA agar media ,then incubated at $25^{\circ} \mathrm{C}$ as described by Hildebrand, (1938). The colony of each fungal isolate was re-cultured on slant medium and kept at $4{ }^{\circ} \mathrm{C}$ as stock for further studies. 


\section{Identification of the isolated fungus}

Morphological characteristics of the fungal isolate was determined in the plant pathology Dept., National Research Center, Cairo (NRC) based on the cultural and morphological characteristics after growing the fungus on specific media. The morphological criteria were compared with the available literature as well as with the description given by (Barent and Hunter, 1977) for the genus Metarhizium.

Pathogenicity test: Healthy Spodoptera littoralis had been reared in the laboratory of Plant Protection Research Institute for several generations under $25 \pm 1^{\circ} \mathrm{C}$ and 50 $60 \%$ Relative Humidity condition. Cotton leaf worm larvae, $2^{\text {nd }}$ instar larvae ( $S$. littoralis) were dipped in each concentration of Metarhizium for 20 seconds ( $\mathrm{Er}$ et al., 2007). Control larvae were treated with sterile water only. All treated larvae were placed in cylindrical cages and fresh castor leaves were added, then covered using cheesecloth. Ten larvae for each cage and three cages as replicates for each treatment in a completely randomized design were used. Treated larvae were kept in a dark champers maintained at an average temperature of $28 \pm 2{ }^{\circ} \mathrm{C}$.

Malformed and dead larvae were checked daily. Percentages of malformed dead cotton leaf warm larvae were calculated. The infected larvae were daily transferred to media in dishes, kept at saturated humidity and at $28 \pm 2{ }^{\circ} \mathrm{C}$ for presence of a sporulating fungal isolate. All experiments were prolonged for 12 days after inoculation. (Fargues et. al., 2001). Data analysis was performed using probit analysis (Finney, 1971).

\section{Data analysis}

Daily corrected cumulative and accumulative larval mortality was reported for Metarhizium isolate and corrected according to Abbott, (1925). The lethal concentration (( $\left.\mathrm{LC}_{50}\right)$ was computed for each of the fungal suspensions through probit analysis using the Propan program.

\section{Isolation of total genome DNA}

Metarhizium isolate was grown into Czapeks Dox broth media followed by 5 days incubation at $25^{\circ} \mathrm{C}$ with shaking at $200 \mathrm{rpm}$. After incubation the mycelium mass was harvested using centrifugation at $6000 \mathrm{rpm}$ for $10 \mathrm{~min}$. The pellets were washed twice with a buffer solution containing 145Mm NaCL; $100 \mathrm{mM} \mathrm{Na2HPO4;} \mathrm{pH} 7.5$ and stored at $20^{\circ} \mathrm{C}$. The pellets were suspended in $500 \mathrm{ml} \mathrm{PBS}$ buffer and kepton ice three times for $20 \mathrm{sec}$. at $60 \mathrm{w}$ to disrupt Metarhizium.Total genomic DNA was isolated 
using a lysozyme/dodecyl sulfate. Lysis method was conducted according to Chang et al., (1995). The mycelia were lysed by the addition of $10 \%$ SDS solution followed by incubation with $100 \mu$ RNase. $10 \mu$ of Proteinase $\mathrm{K}$ solution $(10 \mathrm{mg} / \mathrm{ml})$ was added, to lysedmycelia and incubated for $1 \mathrm{hr}$ at $37^{\circ} \mathrm{C}$. The DNA in the aqueous phase was precipitated with $95 \%$ ethanol followed by washing with $70 \%$ ethanol. The DNA pellets were allowed to dry then dissolved in TE buffer (10 mM Tris HCL, 0.5mM EDT, $\mathrm{pH}$ 8.0) and stored at $20^{\circ} \mathrm{C}$ for further studies.

\section{Amplification of 18srDNA gene}

The Primer sets used for identification of Metarhizium was designed as universal 18srDNA gene for Deutromycetes fungi. The primers sequence for the primer pair was; the forward primer; 5CAGCTCGAAAACAAACCCCG-3 and the reverse primer; 5-AGAGCATCCTAGCAAAGCCG-3. The primer sets generates a 335 bp PCR product with optimal annealing temperature at $55^{\circ} \mathrm{C}$.

The 18s rDNA gene was amplified using conventional PCR. The PCR reactions consisted of ; $12.5 \mu$ l DreamTaq Green PCR Master Mix (2X), $1 \mu$ forward primer, $1 \mu \mathrm{L}$ reverse primer, $2 \mu \mathrm{l}$ Template DNA and water in a total volume of $25 \mu \mathrm{l}$. The PCR reaction conditions were; Initial denaturation at $95^{\circ} \mathrm{C}$ for $5 \mathrm{~min}, 40$ cycles of denaturation at $95^{\circ} \mathrm{C}$ for $30 \mathrm{~s}$, annealing at $58{ }^{\circ} \mathrm{C}$ for $30 \mathrm{~s}$ and extension at $72{ }^{\circ} \mathrm{C}$ for $30 \mathrm{~s}$, and final extension step at $72^{\circ} \mathrm{C}$ for $10 \mathrm{~min}$.

\section{Agarose gel electrophoresis}

The PCR product (50 $\mathrm{\mu l}$ ) was detected by $1.5 \%$ agarose gel electrophoresis running in $1 \mathrm{X}$ TAE buffer, stained with ethidium bromide as described by Sambrook et al., (1989). The amplified DNA fragments were visualized usingUV light transilluminator and the size of expected DNA fragments was estimated as compared to a DNA ladder of 100 to $2000 \mathrm{bp}$ (Bio-rad).The run was performed at $100 \mathrm{~V}$ in BioRad submarine and photographed with Gel Documentation 2000 systems.

\section{Purification of PCR product}

The 18sr DNAPCR products were eluted from agarose gel using the gel DNA extraction kit and purified using a QIA quick gel extraction kit (Qiagen Inc., Germany).

\section{DNA sequencing}

The nucleotide sequence of the purified DNA fragments was sequenced using automated DNA sequencing.The DNA amplicons returned as electropherogram files. 
Electropherogram showed distinct peaks for each base cell as well as high values for each calls. The Primers were easily identified in either the forward or reverse direction in each sequence fragment and easily used to piece together the individual sequence. Sequences obtained for each primer for each isolate had sufficient overlap between them and used to form one continuous sequence (Contig).

Resulted DNA sequences of Metarhizium isolates were aligned using MEGA 5.1 and further analysis was conducted using BioEdit software version 7 (www. MbioNCUs. Edu/bio. Edit). The nucleotide sequence of 18srDNA gene was checked on GenBank for highly similar sequences with known accession numbers. Furthermore, the Metarhizium anisopliae EG016 18s rDNA nucleotide sequence was submitted using NCBI BankIt submission tool and an accession number (KU965593) was assigned for this isolate. The dendrogram showing relationships between the Metarhizium isolate isolated in this study and the other close isolated was constructed using Neighbor joining method.

\section{RESULTS AND DISCUSSION}

\section{Identification of Metarhizium associated with Spodoptera exigua.}

M. anisopliae EG016was isolated from naturally infected pupae of S.exiguae infested cabbage onto SDYA specific medium. The external symptoms such as dead impact, malformation, colour change and mycelium growth was revealed (Fig.1a). Metarhiziumwas purified by hyphal tip assay on SDYA medium and was identified as Metarhizium anisopliae based on the morphological characteristics which werehyaline and branched Conidiophores, formation of asporulating layer; phialides either as single or in pairs, or in whorls; conidia (phialospores) produced in basipetal chains, compacted into columns with long-ovoid to cylindrical and1-celled, shape)as shown in Fig.1b. These results were in agreement with Pik-kheng et al., (2009) and Razinger et al., (2014) who reported that M.anisopliae produced yellow mycelia mat with circular rings of green conidia, fluffy colonies and gave round shape colony on SDYA or Potato dextrose agar (PDA) media. 

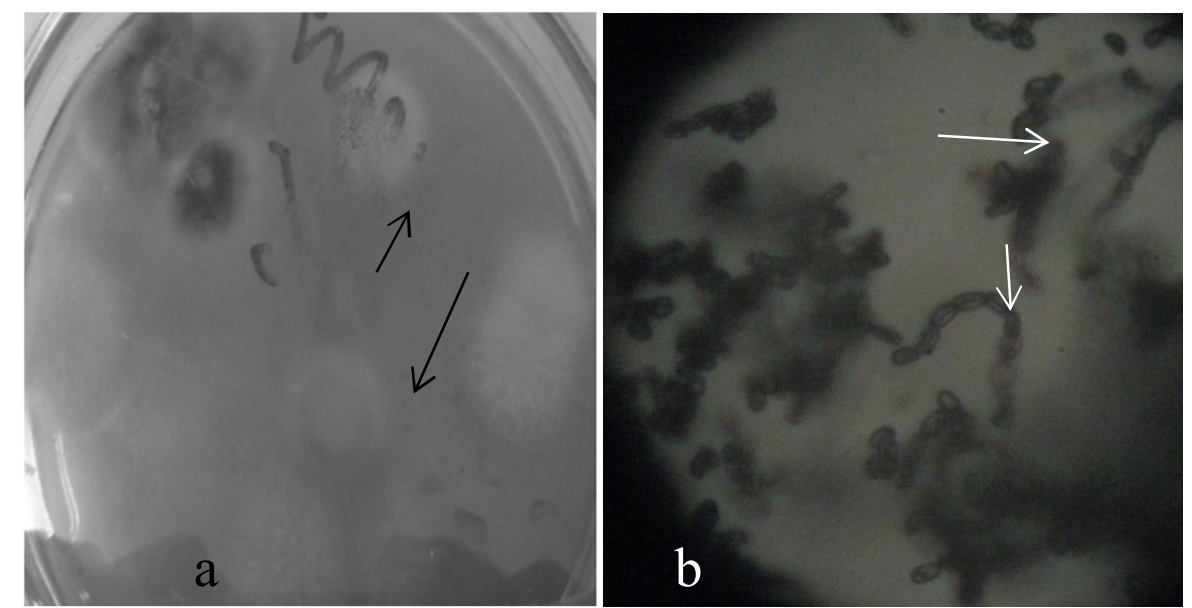

Fig. 1. (a)Metarhizium growth after isolation from the naturally infested cabbage leaves with pupae of S.exiguae (b) Metarhizium conidiophores and magnification at400x.

\section{Entomopathogenicity tests}

The entomopathogenicity tests were performed against $2^{\text {nd }}$ instar larvae of S.littoralis. Results indicated that mortality percentage after 2 days of treatment was $14.6 \%$ for all concentrations, while after 4 days the mortality percentage was $27.1 \%$, then there was a gradual increase in mortality percentage appeared with increasing time elapsed post treatment. The mortality percentage increased to $66.8 \%$ after 12 days as shown by Lotfy et al., (2010). Kumar and Chowdhry, (2004) reported that M.anisopliae gave mortality percentage ranged between $50-92.5 \%$. The larvae showed progressive symptoms of fungal infection; beginning with a stop to eat that was associated with sluggishness. As infection progressed, the larvae became immobilized, moribund and darker in color. These symptoms were similar to those observed by Blanford and Thomas, (2001). Daily corrected cumulative and accumulative larval mortality for M.anisopliae isolate was recorded according to Abbott (1925) as shown (Table 1). In addition, Thompson and Brandenburg, (2005) reported that death caused by the fungi usually was more than 48 hs post infection after attachment of conidia to the insect cuticle. 
Table 1. Cumulative corrected mortality percentage of S. littoralis $2^{\text {nd }}$ instar larvae after dipping on M.anisopliae isolated from S.exigua.

\begin{tabular}{|c|c|c|c|}
\hline Days & \% Corrected mortality & $\begin{array}{c}\mathrm{LC}_{50} \\
(95 \% \text { confidence limits })\end{array}$ & $\begin{array}{c}\text { Slope } \\
\pm \mathrm{SE}\end{array}$ \\
\hline $\mathbf{2}$ & 14.60 & $4.13566 \times 10^{9}$ & $0.5489 \pm 0.3250$ \\
\hline $\mathbf{4}$ & 27.10 & $3.56421 \times 10^{9}$ & $0.3288 \pm 0.2506$ \\
\hline $\mathbf{6}$ & 48.10 & $6.59060 \times 10^{7}$ & $0.3827 \pm 0.2883$ \\
\hline $\mathbf{8}$ & 58.60 & $1.21529 \times 10^{7}$ & $0.3576 \pm 0.2427$ \\
\hline $\mathbf{1 0}$ & 64.10 & $4.62284 \times 10^{6}$ & $0.3510 \pm 0.0953$ \\
\hline $\mathbf{1 2}$ & 66.80 & $1.99296 \times 10^{6}$ & $0.3108 \pm 0.1350$ \\
\hline
\end{tabular}

\section{Molecular characters of 18s rDNA gene}

\section{Total genomic DNA}

Total DNA was isolated from Metarhizium and subjected to PCR amplification and sequencing.The integrity and quantity of purified DNA were confirmed by agarose electrophores (Fig. 2) and the UV spectrophotometer at absorption ratio A 260 / 280 was 1.7 indicating DNA purity. The concentration of DNA was $75 \mu \mathrm{g} / 5 \mathrm{gm}$ mycelium. The results indicated that, Metarhizium mycelium yields high concentration and pure isolated DNA.

\section{8s rDNA gene amplification}

18srDNA gene of Metarhizium isolate was amplified from using conventional PCR with specific primers. The gel electrophoresis of the PCR products showed single intact and specific bands (Fig. 2). The size of the PCR products was found to be $335 \mathrm{bp}$ as compared to the standard DNA ladder as shown in Figure 2.

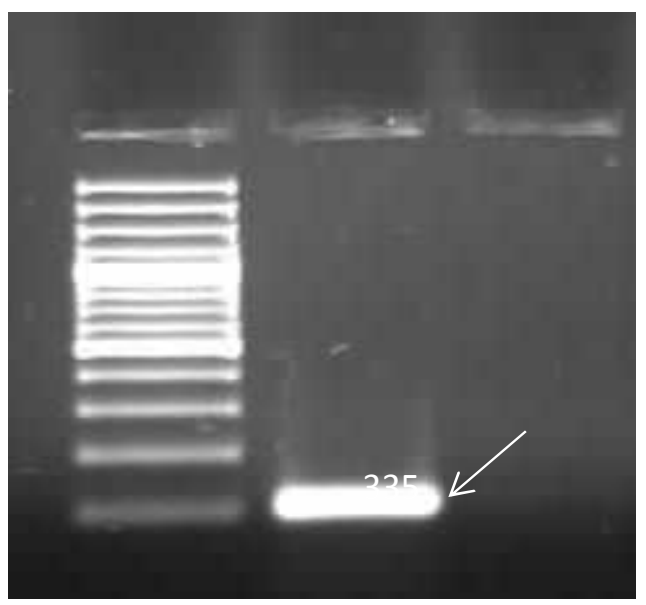

Fig 2. Agarose gelelectrophoresis (1.5\%) showing DNA fragments of 18srDNA gene amplified by PCR using genomic DNA of Metarhizium M denotes DNA leader (100-2000 bp), IL denotes Infected larvae of S.exiguae; HL denotes Healthy larvae of S.exiguae. 
The partial nucleotide sequences of the 18srDNA gene of $M$. anisopliae EG016included 571bp withas shown in Figure 3. The nucleotide sequence was aligned by using MEGA 5.1 program with other highly similar four Metarhizium strains published on Gen Bank (Fig.4). The nucleotide blast confirmed the identification of Metarhizium through sequence similarity with other known published isolates on Gen Bank. The multiple sequence alignment of Metarhizium 18s rDNA nucleotide sequences revealed the variation between this isolate and the other four identified Metarhizium in terms nucleotides addition, substitution and deletion. (Fig. 5).

CAGGCAACTACCTGATCGAGGTCACCTGGATAAAATTTGGGTTGATCGGCAAGCGCCGGCC GGGCCTACAGAGCGGGTGACAAAGCCCCATACGCTCGAGGACCGGACGCGGTGCCGCCGCT GCCTTTCGGGCCCGTCCCCCGGGATCGGAGGACGGGGCCCAACACACAAGCCGTGCTTGAG GGCAGCAATGACGCTCGGACAGGCATGCCCCCCGGAATACCAGGGGGCGCAATGTGCGTTC AAAGACTCGATGATTCACTGAATTTGCAATTCACATTACGTATCGCATTTCGCTGCGTTCTTC ATCGATGCCGGAACCAAGAGATCCGTTGTTGAAAGTTTAAATAATTTATATTTTCACTCAGA CTACAATCTTCAGACAGAGTTCGAGGGTGTCTTCGGCGGGCGCGGGCCCGGGGGCGTAAGC CCCCCGGCGGCCAGTTAAGGCGGGCCCGCCGAAGCAACAAGGTAAAATAAACACGGGTGGG AGGTTGGACCCAGAGGGCCCTCACTCGGTAATGATCCTTCCGCAGGTTCACCTACGGAAACC TTGTTACGACTTITACTTCCA

Fig. 3. The partial nucleotide sequence of 18s rDNA gene of $M$. anisopliae EG016 (KU965593) isolate.

\section{Nucleotide sequence analysis}

The phylogenetic relations between the nucleotide sequence of $18 \mathrm{~s}$ rDNA gene of M. anisopliae EG016 (KU965593) isolate and the closely related known isolates was constructed using neighbor-joining method. The phylogenetic tree of all Metarhizium isolates revealed three clusters of which the $M$. anisopliae under the current study was separated into a single cluster with close relatedness with $M$. anisopliae (KF056846.1) that existed as a separate cluster as well as $M$. anisopliae (JQ284382.1), M. anisopliae (JQ425479.1) and M. anisopliae (JQ284381.1) which constituted a single cluster. 
M. anisopliae
M. anisopliae (KF056846.1)
M. anisopliae (JQ284381.1)
M. anisopliae (JQ425479.1)
M. anisopliae (JQ284382.1)

M. anisopliae

M. anisopliae (KF056846.1)

M. anisopliae (JQ284381.1)

M. anisopliae (JQ425479.1)

M. anisopliae (JQ284382.1)

M. anisopliae

M. anisopliae (KF056846.1)

M. anisopliae (JQ284381.1)

M. anisopliae (JQ425479.1)

M. anisopliae (JQ284382.1)

M. anisopliae

M. anisopliae (KF056846.1)

M. anisopliae (JQ284381.1)

M. anisopliae (JQ425479.1)

M. anisopliae (JQ284382.1)

M. anisopliae

M. anisopliae (KF056846.1)

M. anisopliae (JQ284381.1)

M. anisopliae (JQ425479.1)

M. anisopliae (JQ284382.1)

M. anisopliae

M. anisopliae (KF056846.1)

M. anisopliae (JQ284381.1)

M. anisopliae (JQ425479.1)

M. anisopliae (JQ284382.1)

M. anisopliae

M. anisopliae (KF056846.1)

M. anisopliae (JQ284381.1)

M. anisopliae (JQ425479.1)

M. anisopliae (JQ284382.1)

M. anisopliae

M. anisopliae (KF056846.1)

M. anisopliae (JQ284381, 1)

M. anisopliae (JQ425479.1)

M. anisopliae (JQ284382.1)

M. anisopliae

M. anisopliae (KF056846.1)

M. anisopliae (JQ284381.1)

M. anisopliae (JQ425479.1)

M. anisopliae (JQ284382.1)

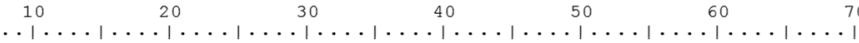
CAGGCAACTACCTGATCGAGGTCACCTGG-ATAAAATTTGGGTTGATCGGCAAGCGCCGGCCG TTCCGTAGGTGAACCTGCGGAAGGATCATTACCGA--GTGCGGGTCCTT-TGGGCCCAACCTCCCATCCG GTAGGAGGAGGTTCTAGCGAGCCCAACCTCCCACCCG TCGGTTCTAGCGAGCCCAACCTCCCACCCG TCCGTAGGTGAACCTGCGGAAGGATCATTACCGAGTGTAGGGTTCCTAGCGAGCCCAACCTCCCACCCG 80 GGCCTACAGAGCGG TGTCTATTGTACCCT-GTTGCTTCGGCGGGCCCGCCGCTTGTCGGCCGC-CGGGGGGGGGCTCTGCCCC TICTCGC 作 TGTTTACTGTACCTTAGTTGCTTCGGCGGGCCCGCATTCAT-GGCCGC-CGGGGG---- CTCTCAGCC

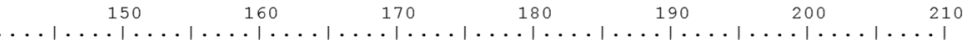
TCGGGCCCGTCCC -- CCGGGATCGGAGGACGGGGCCAACACACAAGCCGTGCTTGAGGGCAGCAATGA CCGGGCCCGTGCCCGCCGGAGACCCCAACACGAACACTGTCTGAAAGCGTGCAGTCTGAGTTGATTGAAT CCGGGCCCGCGCCCGCCGGA GACACCA--CGAACTCTGTCTGATCTAGTGAAGTCTGAGTTGATTGTAT

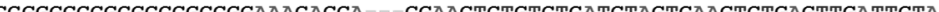
CGAACTCTGTCTGATCTAGTAARTCIGAGTTGATTGTA

$\begin{array}{rrrrrr}220 & 230 & 240 & 250 & 260 & 270\end{array}$ CGCTCGGACAGGCATGCCCCCGGAATACCAGGGGGGCAATGTGCGTTCAAAGACTCGATGATTCACTG -GC--AATCAGTTAAAACTTTCA----ACAATGGATCTCTTGGTTCCGGCATCGA-TGAAGAACGCAGCG CGC--AATCAGTTAAAACTTTCA----ACAATGGATCTCTTGGTTCCGGCATCGA-TGAAGAACGCAGCG CGC CGC--AATCAGTTAAAACTTTCA--ACAATGGATCTCTTGGTTCCGGCATCGA-TGAAGAACGCAGCG

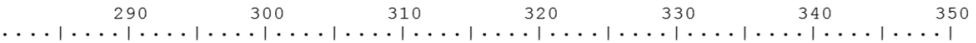
AATTTGCAATTCACATTACGTATCGCATTTCGCTGCGTTCTTCATCGATGCCGGAACCAAGAGATCCGTT AAAT - GCGATAACTAATGTGAATTGCAGA--ATTCAGTGAATCATCGAGTCTTTGAACGCACATTGCGCC AAAT-GCGATAACTAGTGTGAATTGCAGA--ATTCCGTGAATCATCGAGTCTTTGAACGCACATTGCGCC AAAT - GCGATAACTAGTGTGAATTGCAGA - ATTCCGTGAATCATCGAGTCTTTGAACGCACATTGCGCC AAAT-GCGATAACTAGTGTGAATTGCAGA--ATTCCGTGAATCATCGAGTCTTTGAACGCACATTGCGCC

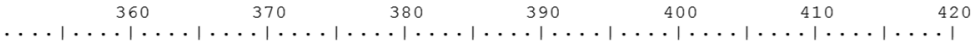
GTTGAAAGTTTTAAATAATTTATATTTTCACTCAG-ACTACAATCT-TCAGACAGAGTTCGAGGGTTCT CCCTGGTATTCCGGGGGGCATGCCTGTCCGAGCGTCATTGCTGCCC-TCAAGCCCGGCTTGTGTGTTGGG CCCTGGTATTCCGGGGGGCATGCCTGTCCGAGCGTCATTGCTGCCCATCAAGCACGGCTTGTGTGTTGGG CCCTGGTA CCCTGGTATTCCGGGGGGCATGCCTGTCCGAGCGTCATTGCTGCCCATCAAGCACGGCTTGTGTGTTGGG

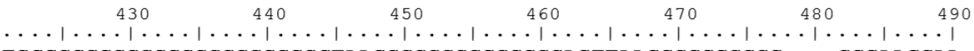
TCGGCGGGCGCGGGCCCGGGGGCTAAGCCCCCCGGGGCCAGTTAAGGCGGGCCCG- CCGAAGCAA TCGCCGTCCCCCTCTCCGGGGGGACGGGCCCGAAAGGCAGCGGCGGCACCGCGTCCGATCCTCGAGCGTA TCGTCGTCCCCTCTCCGGGGGGGACGGGCCCCAAAGGCAGCGGCGGCACCGCGTCCGATCCTCGAGCGTA TCGTCGTCCCCTCTCCGGCGCGGHCGCGCCCCAAAGGCAGCGCCGGCACCGCGTCCGATCCTCGAGCGTA TCGTCGTCCCCTCTCCGGGGGGGACGGGCCCCAAAGGCAGCGGCGGCACCGCGTCCGATCCTCGAGCGTA

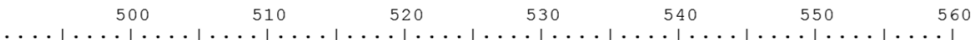
CAAGGTAAAATAAACACGGGTGGGAGGTTGGACCCAGAGGGCCTCACTCGGTAATGATCCTTCCGCAGG TGGGGCTTTGTCA-CATGCTCTGTAGGATTGGCC-GGCGCCTGCCGA-CGTTTTCCAAACCTTCTT TGGGGCTTTGTCA-CCCGCTCTGTAGGCCCGGCC-GGCGCTTGCCGAACGCAAATCAATCTTTTTCCAGG TGGGGCTTTGTCA-CCCGCTCTGTAGGCCCGGCC-GGCGCTTGCCGAACGCAAATCAATCTTTTCCA- TGGGGCTTTGTCA-CCCGCTCTGTAGGCCCGGCC-GGCGCTTGCCGAACGCAAATCAATCTTTTTCCAGG

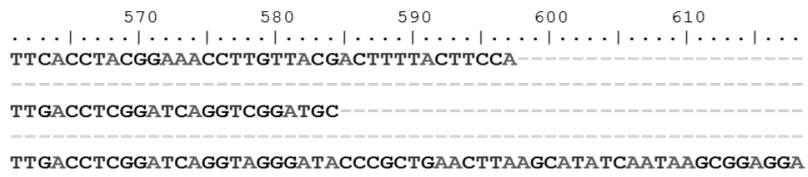

Fig. 4. The Multiple sequence alignment of nucleotide sequences of 18s rDNA gene of M. anisopliae EG016 showing sequence similarity with multiple sequences of four other Meterhizium sp published on Gen Bank.

The molecular identification of Metarhizium species has been performed and contributed to the revision of the taxonomy of Metarhizium. Bischoff et al., (2009) presented a taxonomic revision of $M$. anisopliae cryptic species complex based on a multilocus phylogenetic analysis that discriminated between nine species. A 
phylogenetic tree based on multiple sequence alignment with published Metarhizium isolates on GenBank was carried out in this study as shown in Figure 5 to support the close relatedness of our isolates to those distributed worldwide.

The present work resulted in an efficient method for detection and identification of M. anisopliae that could be applied in further studies as well the bioactivity of the isolated Metarhizium against Spodoptera exigua suggests its potential as a biological control agent that might be promising for future studies to be used commercially.

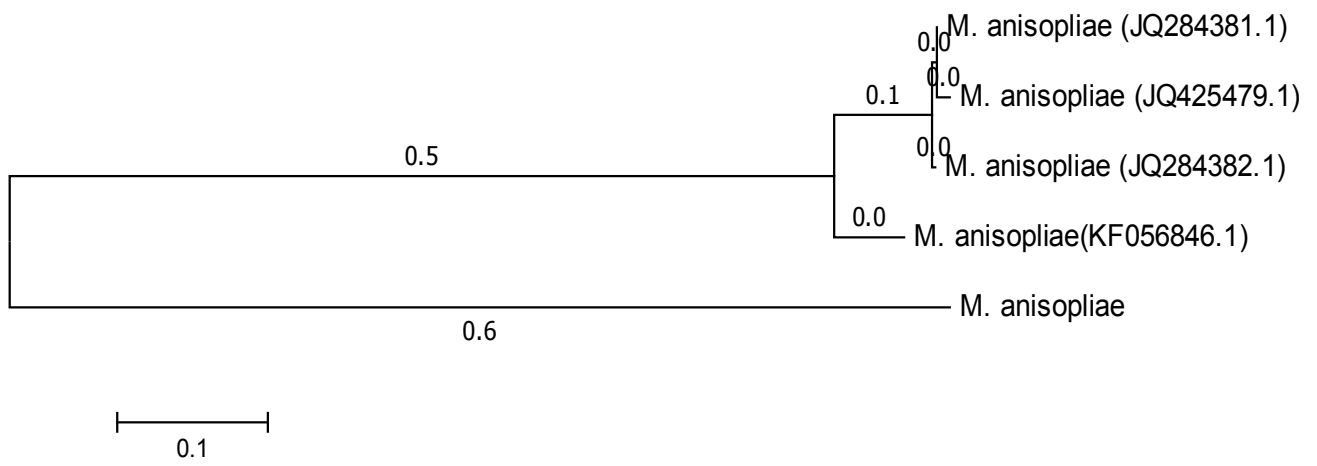

Fig 5. The Phylogenic tree showing the relatedness between all Metarhizium sp based on 18s rDNA nucleotide sequence similarity. The accession numbers for the four published Metarhizium sp obtained from GenBank is shown on the right of each isolate.

\section{REFERENCES}

1. Abbott, W.S. 1925. A method for computing the effectiveness of an insecticide. J. Econ. Entomol.18:265-267.

2. Barent, H. L. and Hunter, B. 1977. Illustrated genera of imperfect fungi. Burgess Publishing Company, Minnesota, 2412 pp.

3. Barra, P., Rosso, L., Nesci, A., and Etcheverry, M. 2013. Isolation and identification of entomopathogenic fungi and their evaluation against Tribolium confusum, Sitophiluszeamais, and Rhyzoperthadominica in stored maize.J.Pest Sci.,86:217-226.

4. Bischoff, J. F., Rehner, S. A., Humber, R. A. 2009. A multilocus phylogeny of the Metarhizium anisopliae lineage. Mycologia 101, 512-530.

5. Blanford, S. and Thomas, M. B. 2001. Adult Survival, Maturation, and Reproduction of the Desert Locust SchistocercagregariaInfected with the Fungus Metarhizium anisopliae varacridum. J. inverteb. pathol., 78(1), 1-8. 
6. Chang, P., Bhatnagar, D., Cleveland, T. E.and Bennett, J. W. 1995. Sequence variability in homologs of the Aflatoxin pathway gene aflR distinguishes species in Aspergillus section Flavi. Appl. Environ. Microbiol. 61: 40-43.

7. Er, M. K., Tunaz, H. and Gökçe, A. 2007. Pathogenicity of entomopathogenic fungi to Thaumetopoeapityocampa (Schiff.) (Lepidoptera: Thaumatopoeidae) larvae in laboratory conditions, J.of Pest Science, 80:235-239.

8. Fargues. J, Smits. N and Rougier. M. 2001. Effect of liquid culture media on morphology, growth, propagule production, and pathogenic activity of the hyphomycete, Metarhizium flavoviride, Mycopathologia 154:127-138.

9. Finney, D. J. 1971. Probit-analysis, $3^{\text {rd }}$ ED., Cambridge Univ. Press, London.

10. Hashim, N. Ibrahim, Y. B. and Tan, Y. H. 2002. Electon microscopy of entomopathogenic fungal invasion on the cabbage-heart caterpillar Crocidolomia Binotalis Zeller, (Lepidoptera: pyralidae), Department of plant protection, Faculty of agriculture, Universiti Putra Malaysia. AJSTD, (2):111-125.

11. Hildebrand, E. M. 1938. Techniques for the isolation of single microorganisms. Bot. Rev., 4: $628-658$.

12. Kumar; $\vee$ and Chowdhry, P. N. 2004. Virulence of entomopathogenic fungi Beauveria bassiana and Metarhiziumanisopoliaeagainst tomato fruit borer, Helicoverpaarmigera, Indian-Phytopathology, 57(2):208-212.

13. Lotfy, D. E., Bekeit, H.K., Hazaa, M. M., Aiat, N. M., El-Dougdoug, K.A.andEmbaby, E. M.. 2010. Isolation, identification and bioassay testing of some entomopathogenic fungi as bio-control agent (BCA) in Egypt.Egyptian J. Appl.Sci.,25(8):225-240

14. Meyling, N.V., Eilenberg, J., 2007. Ecology of the entomopathogenic fungi Beauveria bassiana and Metarhizium anisopliae in temperate agro-ecosystems: potential for conservation biological control. Biol. Control 43, 145-155.

15. Pantou, M. P., Mavridou, A., Typas, M. A., 2003. IGS sequence variation, group-I introns and the complete nuclear ribosomal DNA of the entomopathogenicfungus Metarhizium: excellent tools for isolate detection and phylogenetic analysis. Fungal Genet. Biol. 38, 159-174.

16. Pik-kheng H., Choon, J. B., Kadir, J. and Amartalingam, R. 2009. Evaluation of Metarhizium anisopliae var.anisopliae (Deuteromycetina: Hyphomycete) Isolates and their effects on subterranean Termite Coptotermescurvignathus (Isoptera: Rhinotermitide)-American Journal of Agricultural and Biological Sciences 4(4):289-297. 
17. Razinger, J., Lutz, M., Schroder's, H. J., Palmisano, M., Wohler, C., Urek, G., and Grunder, J. 2014. Direct plantlet inoculation with soil or insect-associated fungi may control cabbage root fly maggots. J. Invertebr. Pathol. 120:59-66.

18. Sabbour, M. M; and Sahab, A.F. 2005. Efficacy of some Microbial control agents against cabbage pests In Egypt, Pakistan-Journal-of-Biological-Sciences, 8(10):1351-1356.

19. Sambrook, J., Fritsch, E. F; and Maniatis, T. 1989. Molecular Cloning: A Laboratory Manual. Cold Spring Harbor Laboratory Press, Nova York.

20. Thompson, S. R. and Brandenburg, R. L. 2005. Tunneling responses of mole crickets (Orthoptera: Gryllotalpidae) to the entomopathogenic fungus, Beauveria bassian. Environ. Entomol., 34: 40-7. 


\section{Metarhizium anisopliae EG016 التعريف البيولوجى و الجزيئى لفطر}

المعزول من حشرة دودة القطن الصغري كعنصر

للمكافحة الحيوية لاودة ورق القطن

داليا السيد محمد لطقى' و احد غمرى عبدالحميد' و خالد عبدالفتاح الاجدج'

$$
\begin{aligned}
& \text { ا ـ معهد بحوث وقاية النبات - مركز البحوث الزراعية - دقى - جيزة - مصر . }
\end{aligned}
$$

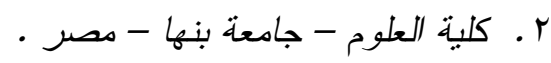

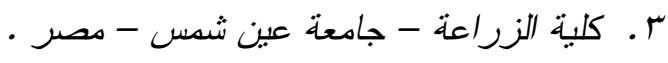

فطر Metarhizium anisopliae ممرض للحشر ات يصيب ويقتل الافات الحشرية ويستخدم

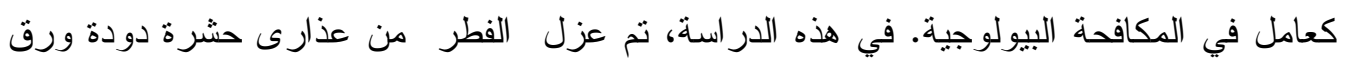

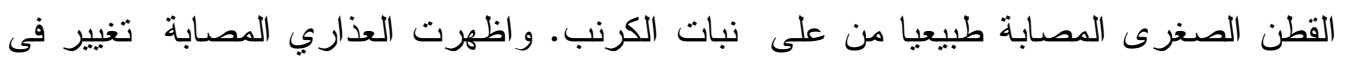
اللون، وتنوه، فضلا عن نمو الميسليوم الفطرية وموت الخلايا.

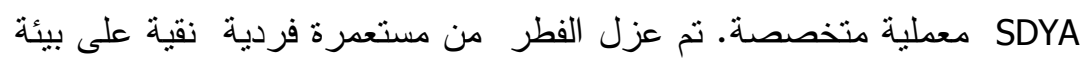

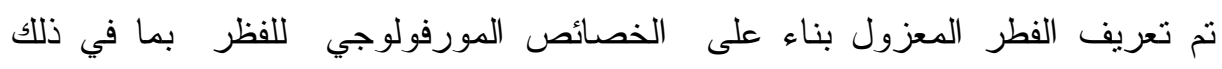

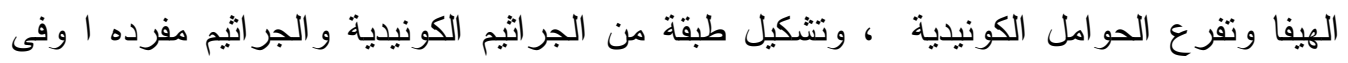
ازو اج او فى سلاسل فى أعمدة منر اصة على شكل حصيرة ولوحظ ونس انها بيضوية طويلة مغزليا

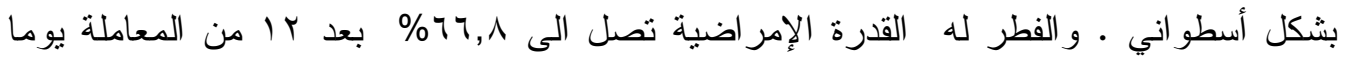

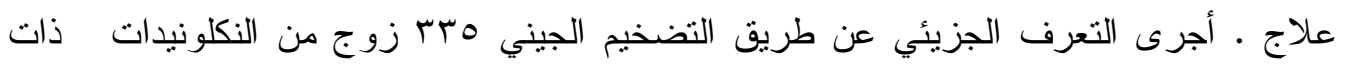

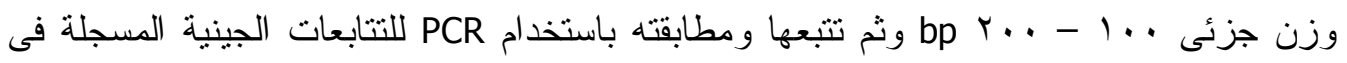
بنك الجينات ونم نسجلها فى بنك الجينات تحت رقم. EG016 (KU965593) isolate.

الكلمات المفتاحية: الفطريات اللممرضة للحشرات، دودة القطن الصغري، عزل، تعريف، DNA, PCR, Nucelotide Sequenc 